\title{
PROFESIÓN E IDENTIDAD EN LA AGRICULTURA FAMILIAR ESPAÑOLA*
}

\author{
JUAN JESÚS GONZÁLEZ y CRISTÓBAL GÓMEZ BENITO \\ Sociología II. UNED
}

PALABRAS CLAVE ADICIONALES

Cambio social, Sociedad rural, Estructura social agraria, España.

\section{ADDITIONAL KEYWORDS}

Social Change, Rural Society, Agricultural

Social Structure, Spain.

RESUMEN. Este artículo analiza las posibilidades y límites de la profesionalización agraria en España desde el punto de vista de las opiniones y actitudes de los agricultores que tienen la agricultura como actividad principal. El artículo permite identificar un núcleo de agricultores más bien jóvenes, con explotaciones medio-grandes y de orientación preferentemente hortofrutícola, que se autoidentifican como profesionales o empresarios y que presentan un relativo cumplimiento del ideal profesional. Se trata, sin embargo, de un proceso incipiente que tropieza con todo tipo de limitaciones, no solo actitudinales, sino también institucionales, relativas, por un lado, a la propia naturaleza de la agricultura familiar y, por otro, a la ausencia de un marco político-institucional adecuado.

\footnotetext{
- Una primera versión de este trabajo fue presentada en el Seminario sobre "La agricultura española en el cambio de siglo", patrocinado por la Universidad de Valencia y la UIMP (Valencia, 5-7 de julio de 2000). Los autores agradecen los comentarios y críticas de los asistentes y, en particular, de Joan Romero, que ejerció de comentarista en aquella ocasión. Agradecen, asimismo, al CIS y al MAPA el apoyo y las facilidades dadas en el transcurso de la investigación que se detalla en el Anexo metodológico.
}

Revista Internacional de Sociología (RIS)

Tercera Época, $\mathrm{n}^{\circ}$ 27, Septiembre-Diciembre, 2000, pp. 41-69. 


\section{INTRODUCCIÓN}

Es dificil encontrar términos al mismo tiempo tan profusos y tan polisémicos en el discurso de los dirigentes y de los responsables agrarios como es el de profesión. Es como si todo el mundo lo considerara más o menos imprescindible a la hora de referirse al sector agrario y, sin embargo, para cada uno tuviera un significado distinto. Esto es así según que hable un dirigente sindical o un consejero de agricultura del gobierno de una Comunidad Autónoma, pero varía también según que el dirigente o consejero se sitúe más o menos a la izquierda o la derecha del espectro político. Unos pondrán el énfasis en la cualificación técnica, en tanto que otros lo asociarán a una mayor o menor vinculación al campo; unos lo asociarán a derechos de producción y explotación, en tanto que otros pensarán que, si de derechos se trata, por qué no de propiedad.

El objetivo principal de este artículo es introducir un poco de claridad y orden en la discusión sobre la profesionalización agraria. Para ello proponemos como modelo de análisis lo que consideramos un modelo mínimo de ideal profesional, es decir una serie de requisitos imprescindibles para que se pueda hablar de profesionalización. Vaya por delante que no esperamos resultados espectaculares de la aplicación de este modelo al colectivo de los agricultores españoles. Las razones son varias. En primer lugar, porque hablar de profesionalización agraria es casi una contradicción en los términos, dada la dificultad de separar derechos de propiedad y de explotación en negocios de carácter familiar. De ahí que prefiramos hablar de profesionalización de los agricultores como un proceso, pero un proceso nunca culminado, por cuanto, de culminarse, supondría la desaparición de la agricultura familiar tal como hoy la conocemos.

En segundo lugar, porque el caso español se caracteriza precisamente por la casi total ausencia de un marco institucional adecuado para el desarrollo del profesionalismo en la agricultura. Ni por el lado de la administración, en lo que se refiere al diseño de las políticas agrarias, ni por el lado del sector, en lo que se refiere a su capacidad de auto-organización y, por ende, a su capacidad para controlar las entradas en el sector y defenderse del intrusismo, se dan las condiciones institucionales típicas de un entorno profesional.

En consecuencia, lo que cabe esperar del colectivo de los agricultores y ganaderos españoles en su conjunto es un cumplimiento del ideal profesional dentro de límites modestos, al tiempo que diferencias significativas en función de variables tales como la edad de los agricultores, el tamaño de la explotación $\mathrm{o}$ la orientación productiva.

El lector puede preguntarse por qué hacer de la profesionalización nuestra perspectiva de análisis si tan sólo cabe esperar un escaso cumplimiento del ideal profesional implícito en nuestro modelo. Creemos que merece la pena detenerse aquí por un momento antes de exponer los resultados del estudio, a fin de encuadrar el problema en el marco más amplio del proceso desfamiliarización 
de la agricultura que hemos argumentado en trabajos anteriores (González y Gómez Benito, 1997; Gómez Benito y González, 2000).

En principio, la agricultura puede desfamiliarizarse de dos maneras. La primera es la via profesional de separación entre propiedad y explotación o, si se prefiere, entre derecho de propiedad y derecho de explotación - podemos aplicar también aquí la distinción convencional entre propiedad y control, entendido éste como capacidad de asignación de los recursos productivos. Esta ha sido la vía preferente de la llamada política socioestructural durante los últimos cuarenta años. En último término, esta política trata de sustituir los criterios tradicionales de tipo familiar por criterios de corte profesional, así como de sustituir criterios de herencia patrimonial por criterios de racionalidad empresarial (González, 1990). Podemos llamarla vía francesa de modernización agraria, donde modernización tiene un significado preciso: profesionalización (Champagne, 1986 y 1987, y Maresca, 1986). En tal caso, la desfamiliarización se produce como consecuencia de que la transmisión y asignación de recursos deja de ser monopolio de las familias y pasa a depender de instancias públicas participadas por las organizaciones agrarias. Recordemos a Coulomb (1985): "la política de estructuras no se da más que en las regiones donde el movimiento social y local la ha impuesto".

Pero hay otra manera de desfamiliarización, que consiste en la desfamiliarización del trabajo. Es la vía espontánea a la desfamiliarización, es decir la que siguen las familias cuando tienen monopolio de decisión. Es claro que influyen factores tecnológicos y que esta forma de desfamiliarización es tanto más fácil cuanto más mecanizables sean las tareas, pero influyen también procesos sociales como la desvinculación de la mujer y de los jóvenes respecto de las tareas agrarias (González et al., 1985 y Gómez Benito et al., 1999). Es así como surgen explotaciones unipersonales donde antes eran familiares a todos los efectos (Blanc et al., 1990; Arnalte et al., 1997; Gómez Benito y González, 2000).

Ya nos hemos referido en otro lugar, a esta segunda vía al hablar de los efectos perversos de las estrategias familiares (González, 1993). ¿Dónde radica la perversión?. A nuestro juicio, la perversión es consecuencia de que la desfamiliarización afecta a un ámbito de la explotación agraria: el laboral, mientras el ámbito de la propiedad y el control permanece familiarizado. Salvando las distancias, es como cambiar el modo de producción manteniendo las relaciones sociales de producción. El primero deja de ser el modo de producción doméstico tradicional para convertirse en modo de producción unipersonal; en virtud de ese proceso, cuando el titular o jefe de explotación necesita mano de obra, ya no recurre a la familia, sino a terceros (asalariados, inmigrantes, empresas de servicios, etc.), al tiempo que la familia en su conjunto sigue detentando capacidad decisoria sobre las cuestiones principales de la explotación (compraventa de tierras, inversiones, etc.). Esto es lo que se observa, al menos, en las investigaciones hechas al efecto (Arnalte et al., 1997; Gómez Benito et al., 1999). 
En ausencia de un marco regulador de los derechos de producción y explotación, parece claro que esta situación tiene unos beneficiarios: los coherederos, cuyos intereses prevalecen como si de una nueva clase de rentistas se tratara. Y una víctima: el sucesor, cuyos intereses quedan a merced de arreglos domésticos y de los avatares del mercado de la tierra.

El problema no es, por tanto, la desfamiliarización de la agricultura, que en sí misma no es ni buena ni mala (es tan sólo un signo de los tiempos). El problema es que, una vez más, la agricultura española está siguiendo la vía menos recomendable (González, 1990), pues mientras la clase política prefiera, tal como viene haciendo en España, dejar toda capacidad de decisión en manos de las familias, la resultante final de este proceso dependerá de la estrategia doméstica y de la correlación de fuerzas en el seno de ellas. Y mientras la agricultura, retórica aparte, siga siendo sinónimo de precariedad laboral y de falta de consideración social, dicha resultante será un mecanismo de selección negativa de los futuros agricultores, en virtud del cual las familias reservarán para la explotación a los hijos con menos iniciativa (Benelbas, 1983).

Este es, en suma, el problema, pues lo que está en juego en esta discusión es el mecanismo de selección de los agricultores. Si la vía a seguir es la profesionalización, cabe la posibilidad, aunque no la garantía, de que la selección sea positiva. En caso contrario, el resultado está cantado: ¿quién se va a quedar en la agricultura sabiendo que no tiene control sobre los recursos productivos y que las actuales reglas de juego garantizan la prevalencia de los derechos de propiedad sobre los de explotación?. Si las explotaciones agrarias estuviesen social y políticamente consideradas como puestos de trabajo, los sucesores podrían conseguir las debidas garantías de estabilidad en el puesto, al tiempo que los poderes públicos podrían hacerles responsables de su gestión. Por el contrario, mientras las explotaciones se consideren patrimonio familiar, todo quedará a merced de la eventual solidaridad de los coherederos.

Este tipo de reflexiones suele ir acompañado de la reivindicación más o menos explícita de un marco jurídico capaz de conferir garantías al sucesor, mediante la discusión y elaboración de un estatuto de la explotación familiar bajo criterios explícitos de profesionalización. Qué duda cabe que cualquier decisión en este sentido sería bien recibida por un sector que todavía cree posible una política agraria sustantiva y diferenciada que sea algo más que la correa de transmisión de las directivas emanadas de Bruselas (Gómez Benito et al., 1999); tanto mejor si esta política fuese resultado del diálogo y del consenso con las organizaciones profesionales agrarias (OPAs, en adelante).

Solo en este contexto adquiere pleno sentido el contrato social tantas veces reivindicado por las OPAs entre el sector y la administración, pues sólo si los agricultores gozaran de las debidas garantías y del reconocimiento de sus derechos profesionales, cabe pensar que la administración pueda hacerles verdaderamente responsables de la gestión económica de sus explotaciones 
(en términos de precios y de calidad alimentaria), y de la gestión ambiental de los recursos que manejan.

A lo largo de este artículo, vamos a dar los siguientes pasos. Comenzaremos, en primer lugar, presentando un modelo mínimo de profesionalismo a fin de hacernos una primera idea sobre la disposición de los agricultores españoles respecto a los factores que definen la profesionalización. No entraremos en la discusión sobre el entramado institucional que sería necesario para culminar con éxito un proceso de profesionalización ni en los factores políticos y sindicales que habrían de acompanarle. Nos interesa, más bien, averiguar en qué medida los potenciales profesionales están en disposición de serlo, en lo que respecta a sus opiniones y actitudes. La literatura sobre el profesionalismo es ingente', pero existe amplio consenso acerca de los factores fundamentales que influyen en el proceso de profesionalización y, en particular, de los tres que vamos a tomar como referencia en una primera aproximación al tema (nuestro modelo mínimo): a) la existencia de un corpus de conocimiento técnico especializado, cuya posesión se considera requisito indispensable del ejercicio de la profesión; b) la capacidad de auto-organización del colectivo en cuestión; y c) la consecución de mecanismos de cierre que aseguren el control del acceso a la profesión frente al intrusismo y la competencia desleal.

En segundo lugar, presentaremos la opinión de los agricultores en su conjunto acerca de cada uno de estos factores y, a continuación, estudiaremos el grado de cumplimiento del ideal profesional implícito en nuestro modelo mínimo. Dedicaremos un apartado a los hábitos asociativos y terminaremos con un análisis estadístico de los determinantes de las nuevas identidades de corte profesional.

Hay un factor crucial en el proceso de profesionalización que está ausente de nuestro modelo mínimo, pero que podemos encontrar en la propia etimología del término. Profesar es, típicamente, hacer profesión de fe o, si se quiere, hacer manifestación pública de creencias, lo que atribuye al ejercicio de la profesión una dimensión moral que es irreductible a su dimensión técnica o mercantil. $\mathrm{Ni}$ que decir tiene que la responsabilidad moral de los agricultores en un mundo amenazado por riesgos de orden alimentario y ecológico va mucho más allá de la tradicional demanda de alimentación barata para las grandes urbes, pero que esa responsabilidad se concrete en un código deontológico trasciende, a su vez, la capacidad del mercado para imponerlo.

\footnotetext{
' Pueden verse, como referencias paradigmáticas, los de Sarfatti Larson (1977) y Abbot (1988). Sobre la profesionalización agraria existe interesante biblografia en francés: véase, por ejemplo, Darré (1984), Muller (1987) y Rémy (1987).
} 
Es aquí donde entra en juego el contrato social al que hacíamos referencia anteriormente. Parece claro que un sector dependiente de ayudas públicas sólo puede seguir esperándolas en la medida en que su actividad esté socialmente reconocida y sancionada, lo que requiere de un proceso continuo de legitimación (escándalos como el de los cazaprimas del lino o el de las vacas locas no ayudan a mantener dichas ayudas). Nada mejor, en ese sentido, que la negociación de un código deontológico orientado a fomentar hábitos de cuidado y atención en la producción de alimentos, por encima de la presión del mercado. Pero que dicha negociación sea factible depende, por lo pronto, de que se promueva un debate público sobre el papel de la agricultura en una sociedad avanzada. No es suficiente con que los agricultores se esfuercen en la vía de la profesionalización. Hace falta también que las administraciones públicas no cierren esa vía.

\section{LA PROFESIONALIZACIÓN, ENTRE LA REALIDAD Y EL DESEO}

En el apartado anterior hemos argumentado por qué la vía de la profesionalización puede resultar deseable. Lo que vamos a plantear a continuación es en qué medida es factible. Conviene comenzar advirtiendo que hablar de profesionalización de la agricultura familiar es, cuando menos, problemático, pues no se dan algunos de los rasgos esenciales del profesionalismo (González, 1990). Tal como se ha indicado anteriormente, se puede hablar de profesionalización de los agricultores como un proceso, pero un proceso nunca culminado, por cuanto, de culminarse, supondría la desaparición de la agricultura familiar tal como la conocemos. Por tanto, sólo cabe hablar de identidad profesional de los agricultores como un tipo ideal de referencia o como un desideratum. Es preciso que nos detengamos en esta cuestión por un momento.

La profesionalización de la actividad agraria está sujeta a muchas restricciones $\mathrm{y}$, por lo pronto, a la mencionada dificultad de separar los derechos de propiedad y de explotación, con el consiguiente solapamiento entre participación en el patrimonio familiar y acceso a la profesión. Esto limita el papel de la capacitación técnica a la hora de seleccionar a los sucesores, por cuanto las familias pueden designarlos a discreción, dando lugar incluso a una selección negativa (pues no se les designa por su capacidad y su iniciativa, sino al revés: por su falta de). De ahí, en parte, que los esfuerzos de las administraciones públicas en pro de la profesionalización del sector estén limitados, en la práctica, a la formación técnica (pues si no hay requisitos de cualificación ex-ante, hay que suplirlos ex-post).

Existen, por otra parte, las llamadas organizaciones profesionales agrarias (OPAs), pero a poco que nos fijemos podemos observar que no cumplen más que parcialmente los objetivos de las organizaciones profesionales propiamente dichas, toda vez que carecen de mecanismos para hacer lo más importante en 
una profesión: controlar las entradas de sus miembros. El (auto) reclutamiento de los agricultores sigue siendo potestad casi exclusiva de las familias, que ostentan plena capacidad decisoria sobre quién se queda en la explotación y quién se dirige a los estudios $\mathrm{y}$, por esa vía, a más altos destinos.

Dicho lo cual, cabría hablar todavía de una cierta semi-profesionalización, en la medida en que la formación técnica constituye un objetivo indiscutido en el discurso tanto de las OPAs, como de las autoridades del sector agrario. Pero tampoco esto conviene darlo por supuesto.

Vayamos por partes. ¿Qué es lo que caracteriza a un colectivo como profesional?. Fundamentalmente, tres cosas: el valor que concede a la formación técnica específica; su capacidad de auto-organización y de conseguir voz propia en los ámbitos de decisión que le afectan, y su reivindicación de cierre profesional, es decir de mecanismos de control del acceso a la profesión ${ }^{2}$.

Cabe esperar, por tanto, que el colectivo agrario sea tanto más profesional cuanto: a) más valore la capacitación técnica agraria; b) más participe en organizaciones agrarias de interés general (no solo sectorial) y mayor papel reivindique para ellas en la elaboración de la política agraria; y c) más reivindicación haga, por ejemplo, de restricciones de acceso al mercado de la tierra o de control sobre la compraventa de derechos de producción ${ }^{3}$.

Pues bien, lo que vamos a plantear a continuación es en qué medida el colectivo de los agricultores a título principal, es decir de los que se dedican principalmente a la explotación, encaja en este perfil ideal de profesionalismo. A tal fin, nos vamos a servir de la encuesta sobre "Condiciones de vida y trabajo de los agricultores y ganaderos españoles" realizada por el CIS (estudio 2273) en la primavera de 1998 (3.370 entrevistas válidas sobre una muestra teórica de 3.400, estratificadas por edad, hábitat y orientación productiva de las explotaciones). La selección de los entrevistados se hizo a partir de los listados de la Seguridad

\footnotetext{
${ }^{2}$ Un ejemplo tipico de cierre profesional en la agricultura son los bancos de tierras reservados para explotaciones consideradas viables, al modo de las SAFER francesas (Coulomb, 1985; Servolin, 1988).

${ }^{3}$ La siguiente cita ilustra bien este problema: «En los últimos anos se ha incrementado la especulación en los derechos de producción. El valor de los derechos o primas de producción (para producir leche, carne, remolacha, vino, etc.) ha aumentado sus precios. Esos derechos a precios altos no los están pagando precisamente agricultores profesionales, sino personas ajenas al sector (...) Por primera vez un litro de leche de «papel» cuesta más en el mercado (60 pts, de media) que el precio medio percibido por el ganadero ( $45 \mathrm{pts}$.)» La cita procede de «Una nueva Politica Agraria para un nuevo siglo. Propuestas de UPA ante las Eleciones Generales del 12 de marzon, febrero de 2000. Ni que decir tiene que un mercado de compraventa de derechos de producción, tal como el que se ha creado en España en los últimos años, es incompatible con una organización genuinamente profesional de la actividad agraria.
} 
Social Agraria por cuenta propia, lo que asegura su representatividad entre el colectivo de los agricultores a título principal. Este colectivo estaba compuesto, en el momento de realizar los trabajos de campo, por 380 mil afiliados a la Seguridad Social Agraria por cuenta propia (véase Anexo Metodológico).

Comencemos por la formación técnica. En principio, sólo un $12,8 \%$ de los encuestados suscribe la idea de que dicha formación "es indispensable". La gran mayoría se divide a partes iguales entre quienes la consideran "conveniente" (40\%) y quienes consideran "más importante la experiencia práctica" (42\%).

Tampoco en lo que se refiere a la capacidad de organización del sector el dato es espectacular. Es conocida la literatura que pone el énfasis en la debilidad y dispersión del sistema asociativo agrario y en las dificultades del sector para generar un tejido asociativo comparable al de los países del entorno, todo lo cual limita su potencial organizativo. Pese a ello, el colectivo de referencia presenta una tasa de afiliación del $26,7 \%$ (23,4\% si descontamos las organizaciones sectoriales: leche, remolacha, etc.), que supera con claridad la tasa de afiliación en la industria o los servicios.

Con este dato inicial, es de destacar que más de un tercio de estos agricultores $(34,5 \%)$ reivindique un "mayor protagonismo de las organizaciones agrarias" en la regulación de los mercados agrarios, frente a un $30,7 \%$ que reivindica mercados protegidos y un $23,2 \%$ que reivindica libertad de mercado. Es en este punto, por tanto, donde el ideal profesional se presenta con más nitidez, en cuanto reivindicación de un modelo neocorporativo de regulación de mercados agrarios donde las propias organizaciones alcancen más protagonismo.

En coherencia con este ideal profesional-corporativo, un $40 \%$ de los entrevistados reivindica también precios de garantía, frente a un $28,7 \%$ que reivindica precios fijos o administrativos y un $22,3 \%$ que prefiere libertad de precios.

Estas aproximaciones al ideal profesional emergen, no obstante, en el marco de una concepción predominante de la actividad agraria como una actividad abierta a la que se puede y debe acceder sin restricción alguna que no sea la de que "solo deberían estar en la agricultura los que pudieran dedicarse plenamente a ella" (el 51,6\% del colectivo apoya esta idea, frente a un 39,3\% que la rechaza). Las demás restricciones, ya sea por razón de herencia (vía patrimonial) o por razón de una formación especializada (vía meritocrática), son masivamente rechazadas. En coherencia con ello, son mayoría también los agricultores que creen que el mercado de la tierra debería ser totalmente libre $(57,8 \%)$, frente a un $33,4 \%$ que apoya alguna forma de cierre profesional en el acceso a este mercado (por ejemplo, reserva preferente de tierras para agricultores a título principal; opinión suscrita por el 19,3\%).

Todo lo cual indica niveles modestos de profesionalización del sector agrario. Ahora bien, esta situación de conjunto encierra diferencias significativas por 
razón de la edad, el tamaño de la explotación, la orientación productiva, etc. A poco que nos fijemos, podemos encontrar, por ejemplo, que los más jóvenes puntúan más alto en cualquiera de los indicadores mencionados. Pero no se trata solo de eso, sino de que estas mayores puntuaciones no hacen sino señalar la emergencia de nuevas identidades de corte profesional o empresarial que compiten con las identidades tradicionales, ya estén ligadas al trabajo o a la propiedad de la tierra. Tanto más cuanto que las organizaciones que se hacen llamar profesionales (las OPAs) han puesto en circulación discursos que encuentran anclaje en estas nuevas identidades, poniendo más o menos énfasis, según los casos, en el componente profesional o empresarial. Es de esperar, por tanto, que los rasgos que hemos identificado como característicos de la profesión estén tanto más arraigados cuanto más los agricultores se identifiquen ellos mismos como profesionales o empresarios.

Cabría incluso contraponer estas nuevas identidades de tipo profesional y empresarial entre sí, tal como hizo Pérez Díaz en su conocido estudio de los "nuevos agricultores" (1983). Pero los datos disponibles sugieren que estas nuevas identidades representan, más que dos concepciones alternativas de organización del sector, variaciones en el proceso, siempre inconcluso, de profesionalización agraria, del que serían una especie de vanguardia.

En el caso de Pérez Díaz, su estrategia consistió en elaborar unos tipos ideales de profesionalismo y de espíritu empresarial y contrastar empíricamente la medida en que un cierto tipo de agricultores (más bien grandes, de comarcas dinámicas, de orientaciones productivas orientadas al libre mercado, etc.) se ajustaba a ellos. En nuestra encuesta, hemos preguntado a los propios agricultores: "Un agricultor es a la vez muchas cosas, pero, si tuviera que elegir una de las siguientes, ¿qué cree Vd que es lo que mejor define a un agricultor?"” Las respuestas posibles eran: un agricultor es, ante todo, un propietario, un trabajador, un profesional, un empresario o un poco de cada cosa (esta última respuesta no era mencionada por el entrevistador). A continuación se trató de averiguar en qué medida sus respuestas se correspondían con sus comportamientos en relación con los rasgos que habíamos establecido como característicos del ideal profesional.

En lugar de establecer una contraposición entre profesionales y empresarios, tal como hacía Pérez Díaz, hemos supuesto que la contraposición más importante es la que se da entre las identidades tradicionales y las nuevas, de manera que podemos establecer un eje donde los que se autoidentifican como empresarios o

\footnotetext{
${ }^{4}$ Se trata, por tanto, de una pregunta proyectiva. Cabria haber preguntado qué es lo que se considera Ud., pero la experiencia de este tipo de preguntas señala que los resultados son parecidos en ambos casos, si bien las preguntas proyectivas facilitan las respuesta.
} 
RIS

REVISTA INTERNACIONAL DE SOCHOLOCI

N• 27, Septiembre - Diciembre, 2000

JUAN JESÚS CONZÁLEZ y CRISTÓBAL CíMEZ

profesionales se sitúan en el polo del profesionalismo y los que lo hacen como propietarios o trabajadores, en el polo opuesto.

Pues bien, la identificación del colectivo de los agricultores a título principal en su conjunto toma como referente la figura del "trabajador": la mitad de estos agricultores se identifica así, siendo el trabajo en el campo lo que les define. Las demás opciones: "profesional" (14,8\%), "empresario" (12,3\%), "propietario" $(6,4 \%)$ o "un poco de cada cosa" (eclécticos) $(12,7 \%)$ son minoritarias. La condición de «trabajador» no es sólo la característica principal de la ocupación, sino también su referente estratégico. Como han puesto de manifiesto estudios anteriores, el objetivo estratégico de la mayoría de los agricultores familiares ha sido equiparar sus rentas y condiciones de vida a los trabajadores de los demás sectores $\mathrm{y}$, en definitiva, a los empleos que han sido destino principal de sus hermanos y allegados (Arribas y González, 1984; más adelante volveremos sobre este asunto).

Para la mayoría de los agricultores del colectivo que ha sido objeto de nuestro estudio (agricultores a título principal), se mantiene esta identificación, al tiempo que se constata la pérdida de centralidad de la propiedad como definitoria de status, elemento éste que era característico de la agricultura tradicional. Lo que define a la agricultura es, para ellos, la dedicación plena a la actividad y, por ende, el trabajo, pero sin que esto impida la emergencia de nuevas identidades, de corte profesional o empresarial, entre los más jóvenes.

Conviene, por tanto, observar la distribución de las respuestas según el grupo de edad (distinguiendo entre menores de 35 años, de 35 a 54 y entre 54 y 65 años, a los que nos referiremos como jóvenes, adultos y viejos, respectivamente), tal como queda reflejado en la tabla 1.

El contraste entre jóvenes y viejos es claro: mientras estos últimos se sienten mayoritariamente identificados en su condición de trabajadores, entre los jóvenes emergen con fuerza las nuevas identidades de profesional y empresario. La edad se configura, por tanto, como un factor decisivo a la hora de entender

Tabla 1.

Identificación de los agricultores, según grupo de edad.

\begin{tabular}{lrrrr}
\hline & $<35$ & $35-54$ & $>54$ & Total \\
\hline Empresarios & 17,1 & 12,9 & 8,5 & 12,3 \\
Profesional & 19,1 & 15,4 & 11,4 & 14,8 \\
Ecléctico & 13,0 & 12,9 & 12,4 & 12,7 \\
Propietario & 4,9 & 6,5 & 7,2 & 6,4 \\
Trabajador & 45,0 & 50,7 & 58,2 & 52,0 \\
Ns/Nc & 0,9 & 1,4 & 2,3 & 1,7 \\
\hline
\end{tabular}


la redefinición de la identidad sociolaboral de los agricultores, con lo que las identidades tradicionales, tanto la de trabajador como la de propietario, van perdiendo vigencia entre los jóvenes.

Esta redefinición depende, por otro lado, de los llamados factores estructurales: tanto el tamaño de la explotación como su orientación productiva influyen de manera no menos decisiva. Por lo que se refiere al tamaño, es preciso tener en cuenta que los que se identifican como profesionales o empresarios están al frente de explotaciones que superan los 60 mil euros de margen bruto, lo que duplica la dimensión de quienes se identifican como trabajadores ( $33 \mathrm{mil})$. Entre medias se sitúan los eclécticos (41,5 mil) y los propietarios (37,9 mil).

Hay que tener en cuenta, al mismo tiempo, que estas diferencias observables en términos de Dimensión Económica ${ }^{5}$ no se corresponden con diferencias equivalentes en términos de Dimensión Laboral de la explotación (medida en Unidades de Trabajo Año: $\mathrm{UTAs}^{6}$ ), tal como se desprende de los datos presentados en la tabla 2 (medias de UDEs y UTAs de cada categoría).

Tabla 2.

Dimensión económica y dimensión laboral de las explotaciones, segín autoidentificación (medias)

\begin{tabular}{lrcrrrr}
\hline & Empresario & Profesional & Ecléctico & Propietario & Trabajador & TOTAL \\
\hline UDEs & 50,63 & 53,16 & 34,58 & 31,57 & 27,50 & 35,44 \\
UTAs & 1,89 & 1,73 & 1,73 & 1,63 & 1,59 & 1,66 \\
& & & & & & \\
\hline
\end{tabular}

Asimismo, influye la orientación productiva (definida como Orientación Técnico-Económica predominante ${ }^{7}$ ) de las explotaciones. Tomando como referencia las cinco principales OTEs, podemos observar que la identidad trabajadora está fuertemente arraigada entre la ganadería herbívora (el $62 \%$ de los ganaderos cuya explotación pertenece a esta OTE así se identifica), pero bastante menos en el resto de las orientaciones (con porcentajes que van del $42,5 \%$ en los cultivos leñosos al $48,5 \%$ en los hortícolas).

\footnotetext{
' La dimensión Económica se mide en UDEs (Unidades de Dimensión Económica) que equivalen a 1.200 euros de margen bruto de explotación.

"Una UTA equivale a 1.826 horas de trabajo y a 228 jornadas/año.

${ }^{7}$ Todas las definiciones técnico-agronómicas que se emplean en este trabajo (UDE, UTA, OTE, etc.) están hechas de acuerdo con la Comunicación de la Comisión Europea 94/C335/01 de 30 de noviembre de 1994, que establece los criterios para el cálculo del Margen Bruto de las explotaciones para cada una de las regiones y cada uno de los cultivos, así como los criterios para la determinación de las orientaciones productivas.
} 
RIS

REVISTA INTERNACIONAL DE SOEIOLOCIA

Por contraste, las explotaciones de cultivos leñosos son donde más arraigan las nuevas identidades (un $38 \%$ se identifica como profesional o empresario), seguidas de la agricultura general y la horticultura (34\% en ambos casos). Las explotaciones de granívoros (31\%) se apartan de la pauta de las de herbívoros (19\%), acercándose a las explotaciones agrarias.

En suma, cuanto más jóvenes sean los agricultores, más grandes sean sus explotaciones y más orientada al mercado sea su orientación productiva, más probabilidad hay de que emerjan las nuevas identidades de tipo profesional o empresarial. Ahora bien, lo que estas nuevas formas de identificación plantean no son tanto, como adelantamos, modelos alternativos de comportamiento, como diferencias de grado o intensidad en su aproximación al ideal profesional. Podemos observar estas diferencias en relación con todas las cuestiones que hemos tomado como indicadores de profesionalismo: el valor que dan a la formación, el modelo de relación con el mercado y su reivindicación de cierre profesional.

\section{GRADO DE CUMPLIMIENTO DEL IDEAL PROFESIONAL}

Antes de entrar en ello, conviene advertir que estas diferencias respecto del ideal profesional van asociadas a otras que definen la posición básica de los agricultores respecto de la explotación, la profesión y la administración pública. Tomaremos como indicador de cada una de ellas: a) la capacidad de iniciativa y, más concretamente, el número de iniciativas de carácter empresarial tomadas en los últimos diez años; b) los hábitos asociativos $\mathrm{y}$, concretamente, el número de asociaciones de corte profesional a las que pertenecen los entrevistados, y c) el número de solicitudes de ayudas de todo tipo hechas a las administraciones públicas (instalación, modernización, etc.), en cuanto indicador de su proximidad y familiaridad con la administración.

Estas diferencias de posición básica van asociadas, a su vez, a otras relativas al tono vital de los entrevistados: su grado de satisfacción con el trabajo, su valoración de lo conseguido en los últimos diez años y su opinión sobre el impacto de la entrada de España en la UE sobre la agricultura. Comenzaremos por estas últimas.

Los que se identifican como profesionales o empresarios son, por lo pronto, quienes: a) se sienten más satisfechos con su trabajo; b) perciben más mejoría en los últimos diez años en la vida de los agricultores; y c) consideran en mayor medida que la integración europea ha sido beneficiosa para la agricultura española. El gráfico 1 nos presenta los saldos de las preguntas respectivas sobre grado de satisfacción con el trabajo, opinión sobre si la vida de los agricultores ha mejorado o empeorado en los últimos diez años (evolución) y opinión sobre si la integración europea ha sido beneficiosa o perjudicial para la agricultura española (balance). Como se puede observar, los saldos son, en general, positivos, excepto en lo relativo a la integración europea, pero siempre son más positivos (o menos negativos) en el caso de profesionales y empresarios. 


\section{Gráfico 1.}

Satisfacción con el trabajo, balance de la integración europea y evolución en los uiltimos diez años, según identificación (saldos).

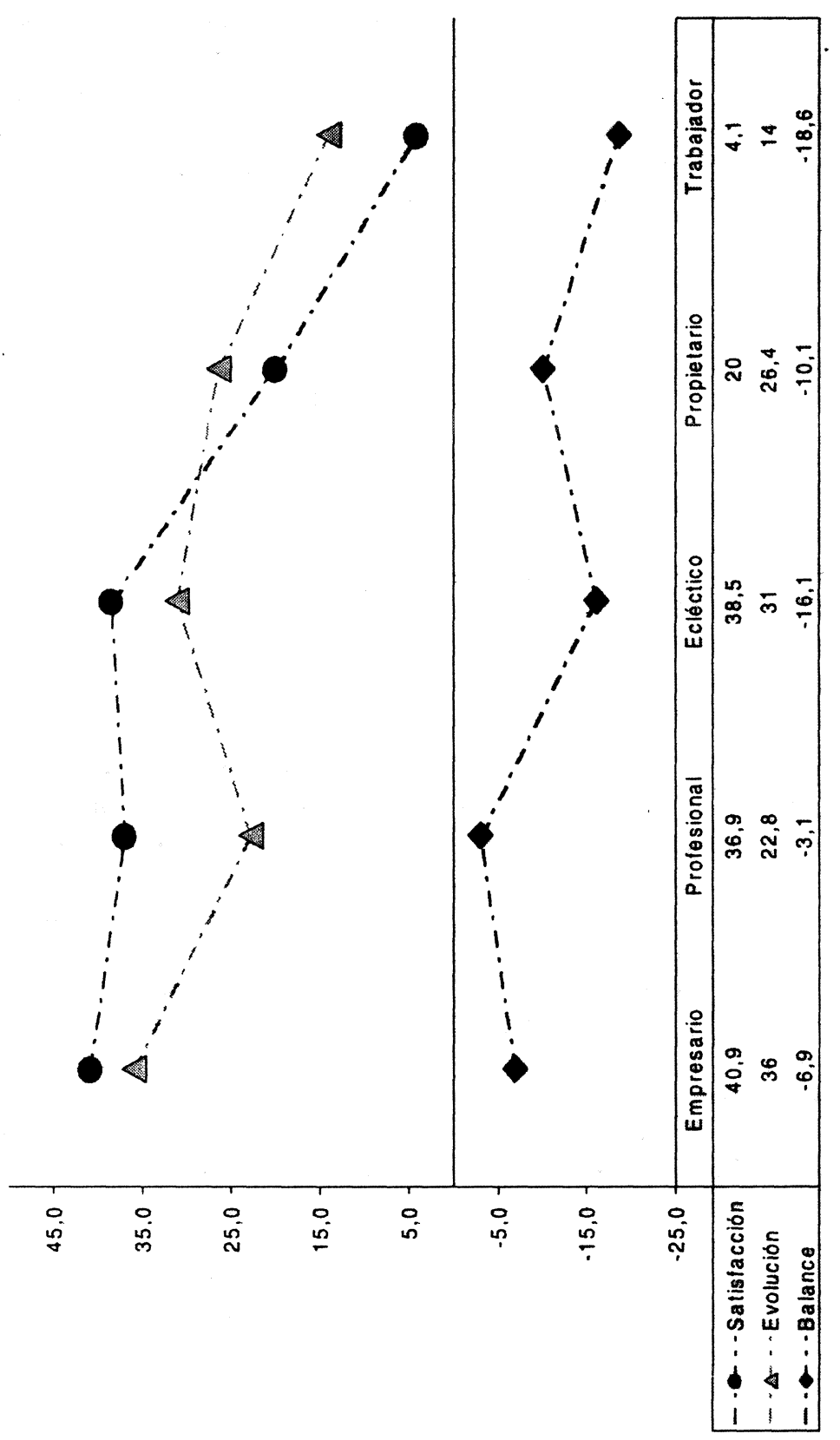




\section{RIS}

En segundo lugar, los que se identifican como profesionales o empresarios son quienes: a) muestran más capacidad de iniciativa empresarial y, más concretamente, han tomado más iniciativas en los últimos diez años del tipo (comprar tierras, cambiar de cultivos/ganados, construir instalaciones, poner en riego, etc); b) participan en mayor medida en asociaciones del tipo: cooperativas, asociaciones de regantes, agrupaciones ganaderas, OPAS, etc, y c) tienen mayor contacto con la administración, tal como se deduce del número de ayudas que han solicitado del tipo: modernización de la explotación, incorporación de jóvenes, comercialización de productos, reforestación, etc. (la tabla 3 resume esta información).

Tabla 3.

Capacidad de iniciativa, relación con la administración y asociacionismo, según autoidentificación (medias)

\begin{tabular}{lccccc}
\hline & Empresario & Profesional & Ecléctico & Propietario & Trabajador \\
\hline Iniciativas & 3,3 & 2,8 & 2,9 & 2,3 & 2,2 \\
Solicitudes & 1,7 & 1,5 & 1,3 & 1 & 1 \\
Pertenencia a asociaciones & 1,5 & 1,5 & 1,2 & 1 & 0,8 \\
\hline
\end{tabular}

Llegamos así al punto crítico de nuestro argumento, según el cual los que se identifican como profesionales o empresarios se erigen en una especie de vanguardia del profesionalismo agrario, tal como se deduce de: a) el valor que dan a la formación (son los que en mayor medida suscriben la idea de que la formación técnica es "indispensable" o, cuando menos, "conveniente" para la actividad agraria, frente a quienes dan más valor a la experiencia práctica: el $60,4 \%$ de los empresarios y el $55,7 \%$ de los profesionales así lo consideran, frente al $51,8 \%$ de los trabajadores y el $41,1 \%$ de los propietarios, que son los que más se alejan del ideal profesional en este punto); b) su reivindicación de mayor protagonismo para las organizaciones agrarias en la regulación de los mercados (el $47 \%$ de los empresarios y el $45 \%$ de los profesionales suscriben esta reivindicación, frente al $35,3 \%$ de los propietarios y el $28,7 \%$ de los trabajadores), y c) su reivindicación de cierre profesional en el acceso al mercado de tierras (el $43 \%$ de ambas categorías reivindica alguna modalidad de reserva de tierras para los agricultores, frente al $34 \%$ de los propietarios y el $27 \%$ de los trabajadores). (El gráfico 2 resume esta información: "opinión sobre temas de la profesión"). 
Gráfico 2.

Opinión sobre temas de la profesión según identificación.

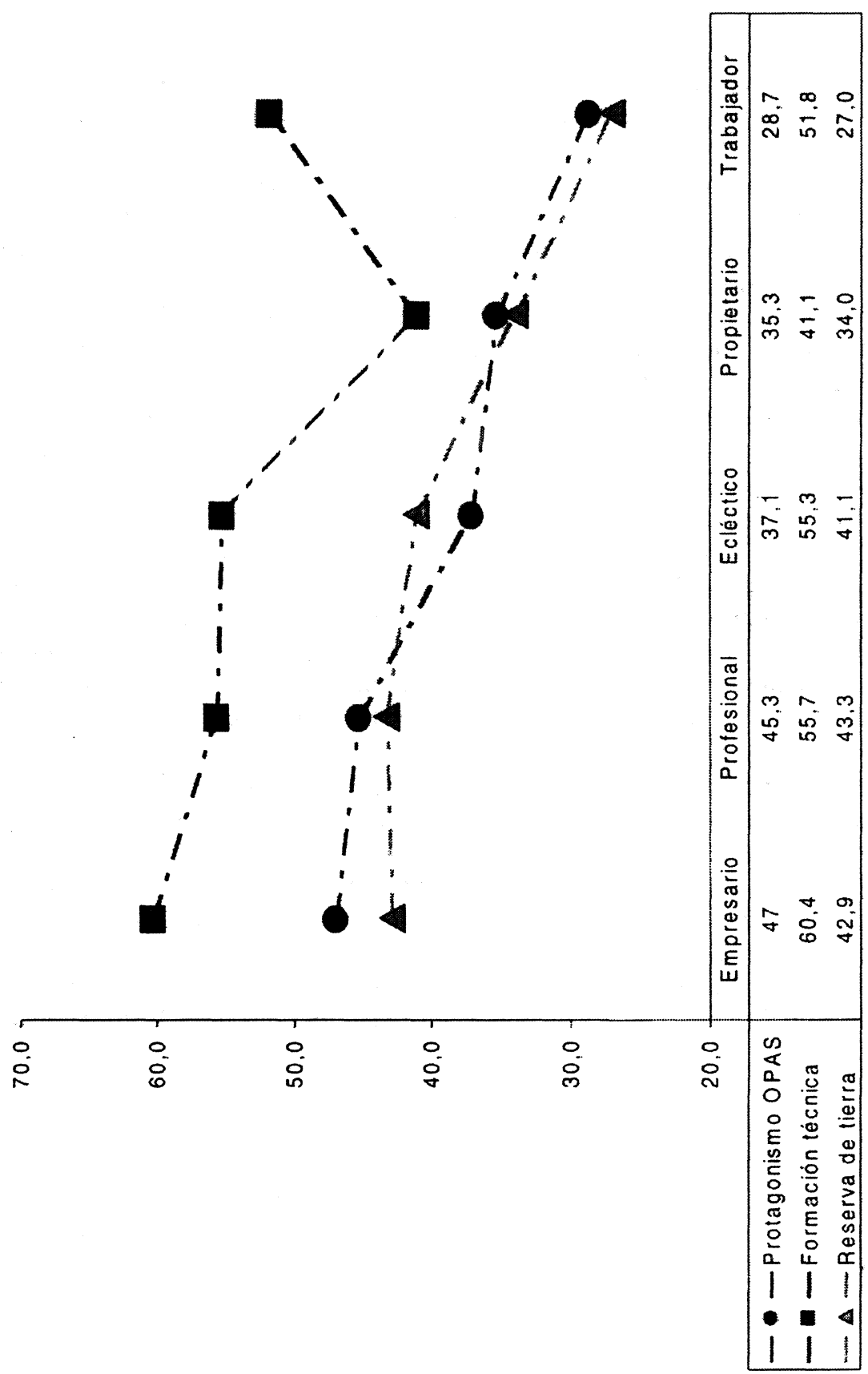




\section{LAS FASES DE LA PROFESIONALIZACIÓN: DE TRABAJADORES A EMPRESARIOS}

Tomando como referencia el colectivo de los agricultores a título principal (justamente aquéllos que tanto las OPAS como las administraciones públicas suelen considerar profesionales stricto sensu), no se puede hablar, por tanto, de un alto grado de ajuste al ideal profesional tal como lo hemos definido, si bien es verdad que emerge una disposición creciente entre los agricultores más bien jóvenes y las explotaciones más bien grandes a favor de dicho ideal. Esta disposición es tanto más elocuente por cuanto va asociada a la autoidentificación de los agricultores en términos de profesión o empresa.

Como se ha indicado, Pérez Díaz presentó en su artículo "Los nuevos agricultores" los hallazgos principales de una encuesta hecha en 1983 a un segmento muy específico de agricultores. Tal como su autor decía en una nota al final del mismo, "en este trabajo se ha elegido una muestra relativamente favorable para la confirmación de la hipótesis de una transformación de los agricultores en empresarios agrarios. Si esto no se confirma en este caso, a fortiori será aún más improbable para el conjunto de los agricultores. Ello permite, en todo caso, explorar la teoría alternativa del profesionalismo agrario" (Pérez Díaz, 1983: 268). Quedaba claro, por tanto, que la encuesta no tenía pretensiones de representatividad y que se trataba de una muestra estratégica.

Con esta premisa, Pérez Díaz diseñó una muestra de 600 agricultores de las comarcas agrarias más dinámicas españolas, con explotaciones de tamaño medio-grande, a partir de la hipótesis de que "la identidad del agricultor moderno es un híbrido entre la identidad de empresario y la de profesional" (1983: 256). Más concretamente, "lo que tenemos, por ahora, es una identidad profesional agraria limitada, con una variante empresarial algo más pronunciada en algunas regiones" (ibídem: 268).

A efectos de nuestra discusión, conviene hacer dos observaciones iniciales. En cuanto al planteamiento, se echaba en falta en dicho artículo alguna referencia al control del acceso a la actividad, en cuanto característica central de las profesiones, más allá de la constatación del alto grado de autorreclutamiento de la actividad agraria ${ }^{8}$. En cuanto al resultado, el colectivo objeto de estudio

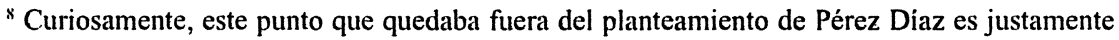
el que ofrece un contraste más claro entre la orientación profesional y la orientación empresarial, por cuanto opone el cierre típico de la organización profesional a la apertura y la libre competencia caracteristica del espíritu empresarial. De ahi que lo que unos ven como intrusismo otros lo vean como garantía de competitividad.
} 
(siempre de acuerdo con la muestra diseñada al efecto) parecía responder a un perfil profesional más bien difuso, mezcla de ideal corporativista y de reivindicación de status de clase media, pero sin llegar a presentar indicios suficientes de identidad empresarial.

Por nuestra parte, creemos que la experiencia de liberalización de mercados agrarios posterior al estudio de Pérez Díaz (a resultas de la integración europea y dentro de los límites que establece la PAC), permite, ahora mejor que nunca, explorar la disposición al libre mercado. Pero en lugar de considerar el libre mercado como un desideratum, intentamos, más bien, observar la medida en que la desaparición de mercados protegidos estimula o va acompañada de rasgos y comportamientos que podemos interpretar en clave de profesionalización. Algunos de ellos forman parte de la visión del orden social y del modelo deseable de organización de la actividad agraria.

En este sentido, cabe esperar que los agricultores postulen una economía regulada o concertada entre el Estado y sus propias organizaciones, tal como sugiere Pérez Díaz y tal como, efectivamente, hemos podido comprobar con nuestro propios datos. Cabe esperar también que sus reivindicaciones no se ajusten a una lógica estricta de paridad de rentas, sino a una más amplia de paridad de status, como señala Pérez Díaz, pero es, en nuestra opinión, dudoso que tal reivindicación tome como referencia a las clases medias (entendiendo por tal a los profesionales). Puede que esta referencia sirva para los agricultores medio-grandes, más bien dinámicos, que centraban el interés de Pérez Díaz, pero no para el colectivo en su conjunto. Los agricultores saben que para conseguir el status de profesionales, necesitan la complicidad del Estado, pero saben también que eso no está en los planes de la clase política. ¿No sería más razonable, en tal caso, pretender igualdad de trato con los trabajadores de otros sectores y con los empleos a los que, en definitiva, podrían aspirar ellos mismos si dejasen la agricultura?

Es dudoso, por tanto, que se postulen a sí mismos como profesionales si no tienen, de hecho, ningún mecanismo de control sobre el acceso a la actividad agraria y, lo que es más importante, no lo reivindican o, si lo hacen, lo hacen sin convicción ( $¿$ de qué sirve, en tal caso, poner tanto énfasis en el servicio a la sociedad, como hace Pérez Díaz, cuando no pasa de ser un gesto retórico?).

La adecuada comprensión de este punto recomienda hacer un breve recordatorio de la experiencia vivida en España por la agricultura familiar durante los años sesenta y setenta, imprescindible, entre otras cosas, para entender el arraigo de la identidad trabajadora en nuestro colectivo de referencia. Como se recordará, la crisis agrícola de los años sesenta colocó a los agricultores enpañoles en la disyuntiva de ajustarse a los cambios de la demanda alimenticia o abandonar el campo. Muchos optaron por esto último, al tiempo que la respuesta de los que se quedaron consistió, preferentemente, en grandes inversiones en puesta en regadío y en otros procedimientos de intensificación 
productiva9. Este esfuerzo inversor se inscribía en el marco de estrategias de maximización del trabajo familiar orientadas a producciones de alto rendimiento por unidad de superficie en mercados no regulados por la Administración (horticultura y cultivos industriales, principalmente).

Fueron precisamente estos enclaves de agricultura intensiva el escenario de los conflictos conocidos como "guerras agrarias" en la primera mitad de los setenta, que dieron lugar a la aparición de un nuevo sindicalismo agrario al margen de la antigua Organización Sindical franquista y de las tradiciones organizativas que habían sido características de la primera mitad del siglo XX. (Arribas y González, 1984). Este movimiento alcanzó su clímax con la "huelga de los tractores" de 1977, en la que el grueso del sector expresó su malestar no sólo por la desprotección de sus productos en el mercado, sino también por los agravios derivados del empobrecimiento demográfico y la precariedad de la vida rural. Pero, a diferencia de las manifestaciones agrarias anteriores, la tractorada no se situó en una posición de beligerancia respecto al pujante movimiento obrero de entonces, sino en disposición de convergencia o, cuando menos, de paralelismo.

"En este sentido [decíamos en referencia al conflicto], la reivindicación de precios se plantea como una demanda de "salario justo"; la demanda de prestaciones de la Seguridad Social como una "equiparación" con los trabajadores de otros sectores, y la exigencia de reforma sindical en el campo es idéntica a la que aspiran los obreros industriales: sustitución de la Organización Sindical por "sindicatos de clase". Por último, la propia expresión del conflicto se realiza mediante la mostración solidaria de la herramienta de trabajo más específica -el tractor-, en actitud de "huelga" - abandono de las faenas de sementera-, con lo que la protesta resulta indisociable de la identidad "trabajadora" del grupo que así se manifiesta" (Arribas y González, 1984: 130).

Analizado en su desarrollo, el conflicto siguió una secuencia que, arrancando de una reivindicación puntual sobre el precio de la patata, dio lugar, primero, a una discusión sobre las estructuras comerciales y la política agraria, para pasar después a formular una reivindicación más amplia de paridad de status con los trabajadores de la industria, mediante la cual los agricultores expresaban la experiencia de proletarización que estaban viviendo. Que el nuevo sindicalismo surgido entonces no haya tenido el éxito organizativo que auguraba aquella movilización sin precedentes, no rebaja un ápice el valor simbólico de aquella novedosa (auto)identificación trabajadora del campo español.

\footnotetext{
"Existe abundante bibliografia sobre la modernización de la agricultura española en los años sesenta y setenta. Un balance panorámico puede encontrarse en el $\mathbf{n}^{\circ} 16$ de Papeles de Economia Española (1983), monográfico dedicado a «La nueva agricultura española».
} 


R IS
PROFESIÓN E IDENTIDAd EN LA AGRICULTURA FAMILIAR ESPAÑOLA

Los posteriores anos ochenta y la experiencia de la integración europea colocaron al sector ante nuevos escenarios y retos. Ante la imparable liberalización del sector, el asociacionismo agrario de corte conservador (en el que confluyeron, a finales de los ochenta, la patronal agraria y el movimiento de Jóvenes Agricultores) trató de aunar su discurso con apelaciones a la profesión, pero era evidente que el sector tenía todavía demasiadas asignaturas pendientes en el proceso de profesionalización.

Tal como se concluía en un estudio dedicado a los agricultores cerealistas, "es, sin duda, la comercialización de sus productos la asignatura pendiente de los cerealistas españoles (...) una actividad que ha estado tradicionalmente monopolizada por el Estado y que en los últimos años ha caído en manos de almacenistas y multinacionales, que intenta ser asumida por los agricultores superando así el anterior estadio de la profesionalización que consistió en el incremento de la productividad. Es el intento de superar la condición de 'productor' y alcanzar la de empresario agrícola..." (Arribas y López, 1989).

Con la liberalización de los mercados, los agricultores dejaron de tener al Estado como paraguas protector y hubieron de enfrentarse al vértigo de la libre competencia. De la sobreprotección anterior sólo quedó la incapacidad de muchos de ellos para defenderse por sí mismos, al tiempo que las apelaciones a la profesión y el espíritu de empresa apenas podían disimular la debilidad del tejido social y asociativo del campo español.

\section{EL PROBLEMA DE LOS HABITOS ASOCIATIVOS}

Enfrentados a un mundo en rápida transformación, los agricultores españoles son conscientes de que su esfuerzo por mejorar y modernizar las explotaciones es a todas luces insuficiente, desde el momento en que el futuro de la agricultura depende cada vez más de la comercialización y la transformación, un área ésta donde su capacidad de actuación es todavía limitada. En la medida en que tales cuestiones superan su capacidad individual, el déficit de hábitos cooperativos y de tejido asociativo se convierte en la sempiterna asignatura pendiente de los agricultores españoles, lo que les deja en clara desventaja respecto a sus colegas europeos.

Por otro lado, el efecto combinado de la construcción europea y de la descentralización autonómica modifica drásticamente la relación de los agricultores con la Administración pública, trastocando el perfil e incluso la propia naturaleza del aparato administrativo. En principio, los agricultores pueden entender el nuevo reparto de papeles, sin que ello suponga necesariamente rechazo al nuevo escenario institucional. Los problemas se plantean en la medida en que los agricultores perciben que el efecto combinado del proceso de transferencias y de la falta de una política agraria nacional conlleva el fin 
R IS

de toda intervención política activa en el campo español que no sea la pura gestión administrativa, sobre el supuesto, inaceptable para ellos, de que la administración pública española ya no tiene otra misión que la de gestionar «lo que viene de Bruselas». Es en este punto donde la pasividad de la nueva administración agraria deviene inhibición ante el excesivo protagonismo de otros agentes económicos, especialmente multinacionales, que amenazan la autonomía del sector y comprometen su estabilidad en el medio plazo.

Estos son los principales retos a los que se enfrenta la agricultura española al día de hoy: ¿cómo responder a esta progresiva sustitución del Estado por el mercado? De acuerdo con la encuesta de Pérez Díaz de 1983, el 26\% de los entrevistados tenía al Estado como principal destinatario de sus producciones; los demás se repartían entre un $51 \%$ que entregaba sus productos a industriales y comerciantes y un $21 \%$ que lo entregaba a cooperativas. De acuerdo con la encuesta que nos sirve de referencia, hoy son algunos más los que venden a industriales y comerciantes (54\%) y bastantes más los que entregan a cooperativas (32\%). Cabría decir, de acuerdo con estos datos, que el cooperativismo gana terreno en la comercialización agraria, pero sigue siendo secundario.

No es fácil, por otra parte, caracterizar el sistema asociativo de la agricultura española en el plano reivindicativo. De hecho, los analistas no terminan de ponerse de acuerdo a la hora de identificar sus rasgos principales: mientras unos destacan las líneas de continuidad con respecto a tradiciones organizativas que arrancan de principios de siglo (Pérez Díaz ${ }^{10}$ ), otros enfatizan, en cambio, la ruptura producida con la transición democrática (Moyano, 1997: 783). Mientras los primeros subrayan la debilidad y dispersión de las organizaciones agrarias (Pérez Díaz, 1991: 11), los segundos destacan, en cambio, la alta densidad asociativa y la capacidad de las organizaciones agrarias en términos de articulación de intereses y de especialización funcional (Moyano, 1997: 774-5).

En cualquier caso, nuestro propósito no es la caracterización del sistema asociativo agrario, sino de la posición de los agricultores respecto a él en un doble sentido: a) en términos de hábitos asociativos $\mathrm{y}$, más concretamente, de densidad asociativa" ${ }^{\prime \prime}$ y b) en términos de su participación en el plano reivindicativo $y$, más concretamente, de afiliación a las OPAs. Las nuevas identidades emergentes presentan un alto índice de densidad asociativa (tanto los que se autoidentifican como profesionales, como los empresarios se acercan a 2, lo que quiere decir que participan en dos tipos distintos de asociación, por término medio), en tanto que las identidades de corte tradicional rondan el 1 (los propietarios se sitúan por encima del 1, en tanto que los trabajadores por debajo) (ver tabla 4).

\footnotetext{
${ }^{10}$ Este autor explica, por ejemplo, la diversidad de siglas que emergen durante la transición (CNAG, UFADE, etc.) por «las tradiciones distintas de los agricultores castellanos y andaluces» (Pérez Díaz, 1991: 13).
} 
Tabla 4.

Indices de densidad asociativa.

\begin{tabular}{cccccc}
\hline Empresario & Profesional & Ecléctico & Propietario & Trabajador & TOTAL \\
\hline 1,95 & 1,87 & 1,39 & 1,21 & 0,92 & 1,27 \\
\hline
\end{tabular}

Pero no se trata sólo de que los que se autoconsideran profesionales y empresarios se afilien a una mayor diversidad de asociaciones (densidad asociativa), sino que se involucran más en ellas, participando más y ocupando puestos de responsabilidad en mayor medida (es lo que aquí entendemos por participación asociativa). Nuevamente, profesionales y empresarios presentan tasas de participación muy superiores a propietarios $\mathrm{y}$, sobre todo, a trabajadores. Mientras los primeros rondan el $80 \%$, los propietarios bajan al $63 \%$ y los trabajadores al 52\% (ver tabla 5). Las diferencias en liderazgo son todavía mayores, pudiendo decirse que una de las características tanto de profesionales como de empresarios es su mayor disposición a, o capacidad de, liderazgo (uno de cada cinco ocupa algún puesto de responsabilidad, en torno al doble que propietarios y trabajadores).

Tabla 5.

Participación asociativa, según identificación.

\begin{tabular}{lccccc}
\hline & Empresario & Profesional & Ecléctico & Propietario & Trabajador \\
\hline Lider & 21,0 & 20,4 & 14,9 & 13,0 & 7,9 \\
Asociado & 59,5 & 59,1 & 48,3 & 50,0 & 43,8 \\
No asociado & 19,5 & 20,4 & 36,8 & 37,0 & 48,3 \\
\hline
\end{tabular}

\footnotetext{
"Entendemos por densidad asociativa la participación en las diversas formas de asociacionismo existentes en el mundo agrario, desde cooperativas hasta sindicatos agrarios, pasando por comunidades de regantes, asociaciones culturales, partidos politicos, etc. En la encuesta de referencia, hemos preguntado por la participación en diez tipos distintos de asociación. Nótese que un agricultor puede pertenecer a más de una asociación de cada tipo (en caso, por ejemplo, de estar integrado en más de una cooperativa), de manera que el indicador elegido mide no el número de asociaciones a las que se pertenece, sino el nimero de tipos distintos de asociación: esto es lo que entendemos aqui por densidad asociativa. Una segunda cuestión a tener en cuenta es el grado de implicación en el tejido resultante de esta diversidad asociativa. En este caso, la implicación la estimamos en términos de ocupación de cargos de responsabilidad en alguna de estas asociaciones, lo que nos permite distinguir entre líderes (cuando se ocupan puestos de responsabilidad) y simples asociados.
} 
RIS

REVISTA INTERNACIONAL DE SOCHOLCGia

V* 27. Septiembre - Viciembre. 2000

JUAN JESÜS GONZŹLLEZ y CRISTÓBAL, GÓMEZ

\section{A MODO DE CONCLUSIÓN}

Hemos visto, en suma, una serie de factores que contribuyen a explicar la formación de nuevas identidades en el campo español: la edad de los agricultores, el tamaño de la explotación, la orientación productiva, la posición ideológica y los hábitos asociativos. ¿En qué medida estos factores contribuyen al proceso de autoidentificación de los agricultores y ganaderos españoles?

Más concretamente, la pregunta se puede formular así: ¿de qué depende que nos encontremos ante una identidad moderna, ya sea empresarial o profesional, en lugar de una identidad tradicional? Para facilitar el análisis, vamos a tomar como ejemplo de esta última la identidad trabajadora y vamos a dejar aparte la identidad propietaria. Hay dos razones que justifican esta decisión. La primera es que, como vimos, la propiedad ha perdido vigencia como referente identitario de los agricultores (recuérdese que sólo un $6 \%$ considera que la propiedad es lo que define a un agricultor hoy día). La segunda es de tipo metodológico, debido a que el modelo de análisis estadístico que vamos a emplear requiere que la variable dependiente sea dicotómica. Desde este punto de vista, la identidad trabajadora se opone con claridad a las identidades empresarial y profesional, pero se opone, a su vez, a la identidad propietaria, de manera que no conviene mezclarlas.

Tomamos como variable dependiente, por tanto, la oposición entre la identidad profesional/empresarial y la identidad trabajadora, y tratamos de explicar la aparición de un tipo de identidad $u$ otro desde tres puntos de vista: a) las características sociodemográficas de los individuos, tales como el sexo y la edad; b) las características estructurales de la explotación, tales como el tamaño y la orientación productiva; y c) los rasgos ideológicos y sociológicos de los individuos, tales como su posición en la escala izquierda-derecha y sus hábitos asociativos.

Concretamente, hemos seleccionado como variables independientes: a) una combinación de sexo y edad; b) el tamaño de la explotación en UDEs; c) la orientación productiva de la explotación según OTE: d) la ideología de los agricultores en términos de escala izquierda-derecha; y e) los hábitos asociativos en términos de participación asociativa, según que sean líderes, simples asociados o no asociados.

Ya hemos visto, tomando cada una de estas variables por separado, de qué manera influyen sobre la identificación de los agricultores. Hay, por supuesto, otras variables que influyen y a las que, sin embargo, no hemos hecho referencia. Una de ellas es obvia y no requiere de mayor comentario: se trata del nivel de estudios. Cabe esperar, como es lógico, que a mayor nivel de estudios mayor sea también la probabilidad de encontrar una identidad profesional. El problema es que la varianza de los estudios es todavía pequeña entre nuestro colectivo, lo que hace que esta variable correlacione mucho con la edad: entre los más viejos son pocos los que tienen estudios y son mayoría los que no tienen ninguno; entre 
los más jóvenes, son mayoría los que tienen algún tipo de estudios, pero son pocos todavía los que llegan al tercer grado.

Con estas premisas, pasamos a presentar los principales resultados de la aplicación del modelo a la encuesta que nos sirve de referencia. La primera conclusión es que la experiencia educativa de los agricultores y la orientación productiva de las explotaciones constituyen los dos principales factores a la hora de explicar el fenómeno identitario. Nivel de estudios y grado de familiaridad con el libre mercado (en particular, cuando se trata de producciones hortofrutícolas, las más experimentadas en este terreno) son claves en el proceso de profesionalización y, más concretamente, de formación de una identidad de corte empresarial/profesional.

En un segundo nivel de influencia, hay tres variables, diversas entre sí, a considerar: el tamaño de la explotación (en téminos de Dimensión Económica), la posición ideológica de los agricultores y los hábitos asociativos. Ya sabíamos que influye el tamaño de la explotación, lo que no sabíamos es cómo. De acuerdo con el modelo, esta influencia es casi lineal y se produce de la siguiente manera: la probabilidad de encontrar una identificación empresarial/profesional aumenta muy poco en el paso de las explotaciones pequeñas (menos de 7 UDEs) a las medianas (entre 7 y 20), pero se duplica si pasamos a las grandes (entre 20 y 60 ) y se triplica si pasamos a las muy grandes (más de 60 UDEs). Influye, por otra parte, la ideología política de los individuos, de tal suerte que los que se autoclasifican en el centro y en la derecha de la escala izquierda-derecha son mucho más proclives a identificarse como empresarios o profesionales (duplican la probabilidad). Por el contrario, los que se autoconsideran de izquierda tienden más a identificarse como trabajadores. Influyen también los hábitos asociativos: los afiliados a algún tipo de asociación duplican, respecto de los no asociados, la probabilidad de encontrar una identidad empresarial-profesional, y los líderes casi la triplican. En otras palabras, cuanto más involucrados están los agricultores en el mundo asociativo, mayor es la probabilidad de encontrar una identidad moderna.

Por último, influye la edad de los agricultores, pero no tanto como podía parecer en la tabla 1, pues una vez que hemos aislado el efecto neto de los factores ( $\mathrm{y}$, más concretamente, hemos separado el sexo y la edad), lo que se observa es sobre todo la influencia del sexo. Los datos del modelo de regresión que mostramos a continuación nos dicen que, tomando a las mujeres como categoría de referencia, la probabilidad se duplica en los varones de menos de 55 años (en tanto que la variación entre los diferentes grupos de varones es mucho menor). Dicho en otras palabras, si la edad parecía tan importante en la citada tabla 1 es en parte porque la distribución de los sexos por edad es desigual, como consecuencia de que la desvinculación de los jóvenes respecto de la actividad agraria es mucho más acusada entre las mujeres que entre los varones (y, por ende, las mujeres agricultoras tienden a concentrarse entre los grupos de más edad). 
R I S

REYISTA INTERNACIONAL UE SOCLOLOCIA

N* 27, Septiembre - Diciembre, 2000

JUAN JESÚS GONZÁLEZ y CRISTÓBAL GÓMEZ

Modelo de regresión logística para estudiar la identificación sociolaboral de los agricultores: profesional/empresario versus trabajador

Las variables independientes son:

. SEXO Y EDAD (grupos de edad de los hombres: <40, 40-54, >54)

NIVEL DE ESTUDIOS: sin estudios, primer grado, $2^{\circ}$ grado, $3^{\circ}$ grado

DIMENSIÓN ECONÓMICA de la explotación en UDES

ORIENTACIÓN PRODUCTIVA DE LA EXPLOTACIÓN en cuatro categorías (oripro4): agricultura general, hortofrutícola, vid-olivar y ganadería

ESCALA IZQUIERDA-DERECHA en cuatro categorías (escala): izquierda ( 1 al 4 de la escala), centro ( 5 y 6 ), derecha ( 7 al 10) y Ns/Nc

PARTICIPACIÓN ASOCIATIVA en tres categorías: líderes, asociados y no asociados

La categoría de referencia son:

. las mujeres (de cualquier edad)

. sin estudios

que trabajan en explotaciones entre 1 y 7 UDES

cuya orientación productiva es la ganadería herbívora

. que Ns/Nc a la escala Izquierda-Derecha

que no están afiliadas a ningún tipo de asociación

La tabla nos da valores para los varones de edad y niveles de estudios siguientes:

(1) $<40$

(2) $40-54$

(3) $>54$

(1) con estudios de primer grado

(2) $2^{\circ}$ grado

(3) $3^{\circ}$ grado

La tabla nos da valores para las explotaciones de las UDEs siguientes:

(1) 7-20 UDES

(2) 20-60 UDES

(3) 60-999 UDES

La tabla nos da valores para las explotaciones de las siguientes orientaciones productivas:

(1) agrícolas

(2) hortofrutícolas

(3) vid y olivar

La tabla nos da valores para las siguientes posiciones ideológicas:

(1) izquierda

(2) centro

(3) derecha

La tabla nos da valores para los siguientes tipos de asociado:

(1) líder

(2) asociado

64 
Dependent Variable.. IDEDOS Identidad profesional/empresario Vs trabajador

-2 Log Likelihood 3002,1324

Beginning Block Number 1. Method: Enter

Variable(s) Entered on Step Number

1.. SEXEDAD sexo y edad

ESTU4 4 niveles de estudios

ORIPRO4 4 orientaciones productivas

DIMECO4 4 niveles de Dimensión Económica

ESCALAID escala IZQUIERDA-DERECHA

ASOTIP tipo de asociado

Estimation terminated at iteration number 4 because

Log Likelihood decreased by less than, 01 percent.

$\begin{array}{lr}-2 \text { Log Likelihood } & 2467,928 \\ \text { Goodness of Fit } & 2235,167 \\ \text { Cox \& Snell - R^2 } & , 207 \\ \text { Nagelkerke - R^2 } & , 284\end{array}$

$\begin{array}{lccc} & \text { Chi-Square } & \text { df } & \text { Significance } \\ \text { Model } & 534,204 & 17 & , 0000 \\ \text { Block } & 534,204 & 17 & , 0000 \\ \text { Step } & 534,204 & 17 & , 0000\end{array}$

Classification Table for IDEDOS

The Cut Value is , 50

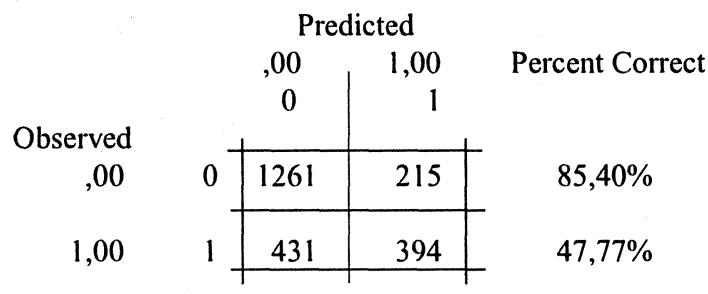

Overall $71,92 \%$ 
RIS

REVISTA INTERNACIONAL DE SOCIOLOGIA

\begin{tabular}{|c|c|c|c|c|c|c|c|}
\hline Variable & B & S.E. & Wald & $\mathrm{df}$ & Sig & $\mathrm{R}$ & $\operatorname{Exp}(B)$ \\
\hline SEXEDAD & & & 26,5093 & 3 & ,0000 &, 0827 & \\
\hline $\operatorname{SEXEDAD(1)}$ & ,6816 &, 1557 & 19,1561 & 1 &, 0000 & 0756 & 1,9771 \\
\hline $\operatorname{SEXEDAD}(2)$ & 6940 &, 1460 & 22,5913 & 1 &, 0000 & ,0828 & 2,0017 \\
\hline SEXEDAD(3) & ,4700 &, 1588 & 8,7558 & 1 &, 0031 & ,0474 & 1,6000 \\
\hline ESTU4 & & & 63,4336 & 3 &, 0000 &, 1383 & \\
\hline ESTU4(1) & ,3888 &, 1330 & 8,5465 & 1 &, 0035 & ,0467 & 1,4752 \\
\hline ESTU4(2) & ,8634 &, 1656 & 27,1955 & 1 &, 0000 & ,0916 & 2,3713 \\
\hline ESTU4(3) & 1,7001 & ,2308 & 54,2440 & 1 & ,0000 &, 1319 & 5,4743 \\
\hline ORIPRO4 & & & 61,0928 & 3 &, 0000 & ,1355 & \\
\hline ORIPRO4(1) & ,7439 &, 1247 & 35,5835 & 1 &, 0000 &, 1058 & 2,1042 \\
\hline ORIPRO4(2) & ,9459 &, 1481 & 40,8214 & 1 &, 0000 &, 1137 & 2,5752 \\
\hline ORIPRO4(3) &, 8168 &, 1758 & 21,5983 & 1 &, 0000 & ,0808 & 2,2633 \\
\hline DIMECO4 & & & 48,7833 & 3 & ,0000 &, 1194 & \\
\hline DIMECO4(1) &, 1202 & , 1493 & ,6485 & 1 & ,4206 &, 0000 & 1,1278 \\
\hline DIMECO4(2) & ,6593 &, 1525 & 18,6815 & 1 &, 0000 &, 0745 & 1,9335 \\
\hline DIMECO4(3) & 1,0167 &, 1771 & 32,9490 & 1 & ,0000 &, 1015 & 2,7641 \\
\hline ESCALAID & & & 45,8121 & 3 &, 0000 &, 1152 & \\
\hline ESCALAID(1) &, 1154 &, 1604 &, 5180 & 1 &, 4717 &, 0000 & 1,1224 \\
\hline ESCALAID(2) &, 7560 &, 1237 & 37,3298 & 1 &, 0000 &, 1085 & 2,1297 \\
\hline ESCALAID(3) & ,6163 &, 1416 & 18,9494 & 1 &, 0000 & ,0751 & 1,8520 \\
\hline ASOTIP & & & 43,0427 & 2 &, 0000 &, 1140 & \\
\hline ASOTIP(1) & ,9800 & ,1648 & 35,3426 & 1 &, 0000 &, 1054 & 2,6644 \\
\hline ASOTIP(2) & ,6495 &, 1185 & 30,0157 & 1 &, 0000 & ,0966 & 1,9145 \\
\hline Constant & $-3,2811$ & ,2001 & 268,8912 & 1 &, 0000 & & \\
\hline
\end{tabular}

\section{ANEXO METODOLÓGICO}

El material empírico en que se apoya este artículo tiene una doble procedencia. Nos apoyamos, por un lado, en un estudio cualitativo realizado por nosotros mismos para el MAPA en 1997, con el título "Estudio sobre las demandas del sector agrario" (producto de un convenio entre el MAPA y el Departamento de SOCIOLOGIA II de la UNED). El estudio estuvo compuesto por 13 reuniones de grupo con agricultores seleccionados en función de las siguientes variables: sexo, edad, orientación productiva, paisaje agrario y tamaño de explotación, lo que proporcionó una muestra muy completa de la agricultura española. Se hicieron, además, quince entrevistas abiertas con funcionarios del MAPA y de las CCAA, antiguos agentes de Extensión Agraria, líderes sindicales, expertos en desarrollo rural, gerentes de cooperativas y dirigentes locales. Los trabajos de campo se realizaron entre los meses de agosto y octubre de 1997. El estudio dio lugar a un extenso informe dirigido por C. Gómez Benito y J.J. González, que fue presentado al MAPA a finales de ese mismo año. 
En cuanto a la encuesta del CIS (estudio 2273), se diseñó una muestra teórica de 3400 titulares o jefes de explotación estratificada por edad, Orientación Técnico-Económica, paisaje agrario y hábitat. La selección del entrevistado se hizo a partir de los listados de la Seguridad Social Agraria, lo que aseguraba que se trataba de agricultores a título principal. Pese a algunos problemas con los listados, la tasa de respuesta fue más que aceptable: en conjunto, se realizaron 1,8 contactos por entrevista, lo que supone una tasa de respuesta del $56 \%$. Por este procedimiento se consiguieron 3370 entrevistas válidas de agricultores con edades comprendidas entre 20 y 65 años, residentes en municipios de menos de 30 mil habitantes. Los trabajos de campo se realizaron en los meses de marzo y abril de 1998. Tanto la metodología detallada como los principales resultados de la encuesta pueden encontrarse en Gómez Benito et al., 1999.

La matriz de datos de este estudio 2273 puede conseguirse en el Banco de Datos del CIS, incluidas las variables técnico-agronómicas a las que hemos hecho referencia en este trabajo (UDEs, UTAs, OTEs, etc.).

\section{BIBLIOGRAFÍA}

ABBOT, A. (1988), The System of Professions. An Essay on the Division of Expert Labor, The University of Chicago Press.

ARNALTE, E. et cal., (1997), "Relaciones familia-explotación en las agriculturas modernizadas. Algunas contrastaciones empíricas en la Comunidad Valenciana", en V. Bretón et al (coord.), La agricultura familiar en España, Universitat de Lleida, Lleida.

ARRIBAS, J.M"a y J.J GONZÁLEZ (1984), "El sindicalismo de clase de la agricultura familiar (Las Cuencas del Ebro y del Duero)", Agricultura y Sociedad, n 31, pp. 121-151, Madrid, MAPA.

BENELBAS, L. (1983), Notas de política agraria, Vicens Universidad, Valencia.

BLANC, M. et al., (1990), “L'agriculture francaise, est-elle encore familiale?”, en P. Coulomb et al., (eds): Les agriculteurs et la politique, París, Presses de la FNSP, pp. 310-330.

CHAMPAGNE, P. (1986), "La reproduction de l'identité", Actes de la Recherche en Sciences Sociales, $n^{\circ} 65$, pp. 41-64, París.

(1987), "Capital culturel et patrimonie economique", Actes de la Recherche en Sciences Sociales, $\mathrm{n}^{\mathrm{0}}$ 69, pp. 51-66., París.

COULOMB, P. (1985), "Derecho de propiedad, derecho de explotación: la mutación de las relaciones sociales en el crecimiento agrícola francés", Agricultura y Sociedad, $\mathrm{n}^{\circ} 35, \mathrm{pp}$. 77-140, Madrid, MAPA.

DARRÉ, J-P. (1984), "La production des normes au sein d'un réseau professionnel", Sociologie du Travail, ${ }^{\circ} 2$, pp. 141-156, París. 
GARRIDO, L y E. GIL (1993), "El concepto de estrategias familiares", en L. Garrido y E. Gil (Coords.), Estrategias familiares, Madrid, Alianza Universidad, pp 13-34.

GÓMEZ BENITO, C. et al., (1999), "Identidad y profesión en la agricultura familiar", Opiniones y Actitudes, $\mathrm{n}^{\circ} 24$, Centro de Investigaciones Sociológicas, Madrid.

GÓMEZ BENITO,C. y J.J GONZÁLEZ (2000), "Familia y explotación en la transformación de la agricultura española", ponencia presentada al seminario sobre La agricultura española en el cambio de siglo, Universidad de Valencia-UIMP, Valencia, 5-7 de julio de 2000.

GONZÁLEZ, J.J (1990), "La incorporación de los jóvenes a la agricultura", Revista de Estudios Agro-Sociales, $\mathrm{n}^{\circ}$ 154, pp 39-96, Madrid, MAPA.

(1993), "Efectos perversos de las estrategias familiares en la agricultura", en L. Garrido y E. Gil (coords.), Estrategias familiares, Madrid, Alianza Universidad, pp. 132-144.

GONZÁLEZ, J.J et al., (1985), Sociedad rural y juventud campesina. Estudio sociológico de la juventud rural, Ministerio de Agricultura, Pesca y Alimentación (MAPA), Madrid.

GONZÁLEZ, J.J. y C. GÓMEZ BENITO (1997), "Clases agrarias, estrategias familiares y mercado de trabajo", en C. Gómez y J.J González (coords.), Agricultura y Sociedad en la España contemporánea, pp. 565-580, CIS, Madrid.

MARESCA, S. (1986), "Le theâtre de la profession", Actes de la Recherche en Sciences Sociales, 65 , pp 77-85, París.

MOYANO, E. (1997), "Acción colectiva y organizaciones profesionales agrarias en España", en C. Gómez y J.J González (coords.), Agricultura y Sociedad en la España contemporánea, pp. 773-795, CIS, Madrid.

MULLER, P. (1987), "Un métier né de la crise: exploitant rural", Sociologie du Travail , n" 2, pp. 459-475, París.

PAPELES DE ECONOMÍA ESPAÑOLA Nº 16 (1983), La nueva agricultura española, Fundación Fondo para la Investigación Económica y Social, Madrid.

PÉREZ, V. (1983), "Los nuevos agricultores", Papeles de Economia Española, n¹6, pp 240-268, Madrid.

(1991), "De campesinos a agricultores: epílogo a Estructura y evolución de las comunidades campesinas de Castilla", Working Paper $n^{\circ} 23$ del CEACS del Instituto Juan March.

RÉMY, J. (1987), "La crise de la professionnalisation en agriculture: les enjeux de la lutte pour le contrôle du titre d'agriculteur", Sociologie du Travail n": 2-87, pp. 415-441, París.

SARFATI, M. (1977), The Rise of Professionalism. A Sociological Analysis, University of California Press.

SERVOLIN, C. (1988), Las politicas agrarias, MAPA, Serie Estudios, Madrid. 
SUMMARY.This article analyzes the possibilities and limits of agrarian professionalization in Spain from the point of view of the opinions and attitudes of the farmers for whom agriculture is their principal activity. The article permits the identification of a hard core of younger farmers with middle-to-large-size holdings and with a preferentially fruit and vegetable orientation, who identify themselves as professionals or businessmen, and who show a relative fulfillment of the professional ideal. It is, however, an incipient process which runs into all kinds of limitations, not only in attitudes but also in institutions: on one hand, relating to the very nature of family farming and, on the other, relating to the absence of an adequate political-institutional framework.

E-mail: jgonzalez@poli.uned.es y cgomez@poli.uned.es 